\title{
Assessing aquaculture sustainability: a comparative methodology
}

\author{
Lazard Jérôme ${ }^{1,{ }^{*}}$, Rey-Valette Hélène ${ }^{2}$, Aubin Joël ${ }^{3,6}$, Mathé Syndhia ${ }^{2}$, Chia Eduardo ${ }^{4}$, \\ Caruso Domenico ${ }^{5}$, Mikolasek Olivier ${ }^{1}$, Blancheton Jean Paul ${ }^{6}$, Legendre Marc ${ }^{5}$, René Francois ${ }^{6}$, \\ Levang Patrice ${ }^{5}$, Slembrouck Jacques ${ }^{5}$, Morissens Pierre ${ }^{1}$, Clements Olivier $^{3}$
}

${ }^{1}$ CIRAD, F-34398 Montpellier, France.

${ }^{2}$ Univ Montpellier I, Fac Sci Econ, F-34960 Montpellier 2, France.

${ }^{3}$ INRA, UMR Sol Agron Spatialisat, F-35042 Rennes, France.

${ }^{4}$ INRA, F-34000 Montpellier, France.

${ }^{5}$ Univ Montpellier 2, IRD, ISEM, F-34095 Montpellier 5, France.

${ }^{6}$ IFREMER, F-34250 Palavas Les Flots, France.

* Corresponding author : Jérôme Lazard, email address : lazard@cirad.fr

\begin{abstract}
:
Little work dealing with the evaluation of aquaculture system sustainability has so far been undertaken on a global and comparative basis. Moreover, such work is mostly based on very unbalanced approaches in terms of the dimensions of sustainable development that are taken into account. The approach adopted in this article is designed to encompass all the dimensions of sustainability including the institutional one (governance). The taking into account of this latter, in particular, together with the role played by aquaculture in sustainability at the territorial level gives the approach its original and innovative nature. The process of establishing the checklist of sustainability indicators in aquaculture relies on a hierarchical nesting approach which makes it possible to link indicators with general sustainability criteria and principles. At once multidisciplinary and participatory, the approach compares several countries with highly differentiated types of aquaculture system. An original finding from this work is that the technically most intensive farming model scores better than more extensive systems, which might have been thought to be closer to natural systems in their environmental dimension and therefore intuitively more 'sustainable'. This result suggests relating sustainability outcomes to the level of control and of devolved responsibilities.
\end{abstract}

Keywords : aquaculture, indicators, co-construction, sustainability

\section{Introduction}

In the last 30 years, aquaculture has experienced an unprecedented development in global animal production with an average yearly growth rate of over $10 \%$ between 1980 and 2000 (FAO 2010). Over the same period, capture fisheries saw their progression gradually grind to a standstill and growth stopped in 1995. The growth of aquaculture, despite its benefits and the fact that it is the only way to meet the increase in demand for sea products, evaluated at $192-270 \mathrm{Mt}$ in 2050 (Wijkström 2003; Merino et al. 2012), raises a certain number of issues directly related to its sustainable development. 
Feed is a crucial topic that is the subject of significant controversy following the emblematic article by Naylor et al. (2000), which showed the impact on catches of the massive use of fish meal and fish oil in fish and prawn aquaculture and advocated a return to less input-intensive aquaculture systems, directly inspired by traditional Asian systems. However, farming systems have continued to intensify and this has led to a sustained increase in the use of fish meal and fish oils (Tacon and Metian 2008). Moreover, Naylor et al. (2000) contrast two aquaculture models: the first, an input-intensive system, particularly as regards fish meal and oils, considered to be non-sustainable, and the second, classically described as extensive or semi-intensive, and considered to be sustainable. Approaches taking into consideration the social domain as a sustainability pillar have provided contradictory results. The various examples that have been studied (Edwards 1999; Irz and Stevenson 2005) show that the fundamental question is whether there are specific aquaculture systems that can contribute to poverty alleviation in parallel with profit-orientated systems.

An analysis of the main reference frameworks such as codes of conduct, guides of good practice, standards, labels etc. (Boyd et al. 2005; FAO 1995; WWF 2008a, 2008b among others) and of initiatives for the construction of sustainable development indicators (Consensus 2005; GFCM 2010) in aquaculture, shows that most of them are based on very unbalanced approaches in terms of the dimensions of sustainable development that are taken into account. Some of them, especially those being implemented on a wide geographical scale, are highly centralised with little reliance on participatory processes, (Mathé et al. 2006). According to Bush et al. (2013), certification in aquaculture, as with organic agriculture, follows an enterprise-level approach. Such narrow definitions of sustainability reflect the structure of standard-setting institutions and the feasibility of measurement and regulation using technical parameters. Even the multi-stakeholder processes used to develop ASC standards have been criticized for adopting a technical focus that reflects the interests and values of the most powerful actors to the exclusion of others (Belton et al. 2012).

Our approach has been designed to encompass all the dimensions of sustainability, including the traditional pillars (economic, social and environmental) as well as the institutional one (governance). A distinctive feature of the approach is that it addresses not only the sustainability of fish farms but also the contribution of aquaculture to the sustainability of areas where such farms are established. This 
the approach recommended by the Millennium Ecosystem Assessment (MEA 2005) and developed by FAO (2008). The approach is both multidisciplinary and participatory and compares several countries and types of aquaculture systems, and results in a diagnosis and global recommendations. Lastly, we compared the sustainability approach based on co-construction, with a standardized and normative approach, i.e. a Life Cycle Assessment (LCA), in order to evaluate the level of convergence of the conclusions from the two types of assessment.

Moreover, our approach is based on the hypothesis that sustainable development is a new reference framework which, in order to be taken on board, requires specific learning processes, the so-called "double-loop learning" of Argyris and Schön (1996). It is not only practices but also values and objectives that have to be modified and it therefore requires a continuous improvement process, starting from sustainable development values or principles that are deemed to be of the highest priority for producers and stakeholders. Sustainability, as it was conceived and addressed in the work carried out under the "EVAD" project from 2005 to 2010 (Rey-Valette et al. 2008), is similar to that defined by Tlusty et al. (2012), i.e. a continuous process, a "journey" rather than a destination in terms of a sustainable, final and ideal aquaculture product.

\section{Material and methods}

\section{The areas}

Six very different areas were carefully chosen in various parts of the world to test the genericity of the method, based on the fish density level in the farming structures, the coastal and rural area, and the regulatory context (table 1$)$.

\section{Rainbow trout farming in Brittany (France)}

Rainbow trout farming is an intensive farming system based on a high input level and on a high stocking rate. Currently, in Brittany, the number of trout farms is decreasing, farms are being concentrated, and overall production is decreasing due to numerous constraints: environmental constraints, social constraints (farming activity acceptance, product image, etc.), along with regulatory and economic constraints (input cost variation, competition with salmon, etc.).

\footnotetext{
${ }^{1}$ Evaluation of aquaculture system sustainability
} 


\section{Mediterranean Sea Bass and Sea Bream farming}

In order to satisfy strong demand (tourists and indigenous population), the production of aquaculture fish (mainly sea bass and sea bream) started in 1980 and increased by $25 \%$ each year between 1990 and 2000 (the current production is estimated at 200,000 tonnes per year). Current production systems (consisting of sea-based cages or land-based raceways) are in conflict with tourism and other models will have to be developed (Rey-Valette et al. 2007). Due to recent crises, aquaculture activity has become concentrated as fish farms have been bought up by major groups.

\section{Fish and shrimp farming in coastal ponds in the Philippines}

Coastal ponds, primarily consisting of extensive shrimp-fish polyculture, account for around $60 \%$ of overall aquaculture production. Observation of the development dynamics of Philippine aquaculture systems highlights the significant flexibility of extensive systems compared to the economic fragility of intensive fish farms when markets are saturated.

\section{Small-scale fish farming in Indonesia}

In Indonesia, although freshwater fish farming is generally a small-scale activity, it nevertheless has one of the highest yearly production rates in the world. Fish farming production systems with high input rates have rapidly developed locally over the last ten years: catfish (Pangasianodon hypophthalmus) in ponds in central Sumatra (Jambi province) and carp and tilapia in floating cages in the Cirata dam reservoir (West Java).

\section{Commercial fish farming in Family Agricultural Enterprises (FAE) in western Cameroon}

Despite a fairly low overall level of aquaculture development, the high plateaux in the Western region are one of the areas in Cameroon where the greatest number of fish ponds have been constructed, with numerous fish farming innovations involving input intensification.

\section{The rationale underpinning the approach}

The process used for the EVAD project is characterized by its transdisciplinary approach (Jahn et al. 2012; Schaltegger et al. 2013), with each phase of the project involving not only human and biological sciences but also the stakeholders who are part of the procedural and participatory approach. The approach relies on the co-construction of indicators for the sustainable development of aquaculture, which then become a tool to drive and legitimize sustainable development (Boulanger 2007). The coconstruction of indicators with broad-based groups of stakeholders enables the development of a 
121 participatory approach and a collective learning process, and facilitates the adoption of sustainable 122 development (Fraser et al. 2006; Hilden and Rosenström 2008; Rey-Valette et al. 2007a, 2007b).

123 Furthermore, the method favours a territorial approach to sustainability, which tallies with Agenda 21 124 at the Rio Earth Summit (Chapter 28) by combining two complementary scales of approach: the 125 sustainability of farms and of the aquaculture sector (sectoral approach) and the contribution of fish farms to the sustainability of the areas where they are located (territorial approach).

128 23. Methodology used to establish the co-constructed check-list of principles and criteria

129 The process of establishing the check-list of sustainability indicators in aquaculture is based on a 130 hierarchical nesting approach which makes it possible to link indicators with general sustainability 131 criteria and principles (Prabhu et al. 2000; Rey-Valette et al. 2008). This type of nesting places the 132 definition of indicators in context enabling them to be linked to territorial and sectoral issues.

133 The co-construction methodology can be divided into three phases: 1) a first preparatory phase to 134 establish a diagnosis of the areas using surveys and expert opinion; 2) a selection/validation phase in 135 order to finalize the list of PCls (principles, criteria and indicators) and 3) an implementation phase to 136 calculate the indicators and validate the diagnosis emerging from these evaluations. These phases 137 are then subdivided into eight stages alternating "laboratory" research (i.e. between researchers) and 138 work with stakeholders in each of the study areas. These stages are alternatively shown in grey and 139 white in figure 1.

14124 . Applying life cycle assessments to the aquaculture systems studied

142 A second type of approach was used in our study, i.e. the Life Cycle Assessment (LCA) method which 143 is a standardized method (ISO 2006a, 2006b; Jolliet et al. 2005) now widely used in the environmental 144 evaluation of fish and aquaculture products (Aubin 2013; Henriksson et al. 2012). The functional unit 145 selected was 1 tonne of aquaculture product delivered to the first buyer. Calculations were based on 146 the CML method (2001) modified in accordance with Papatryphon et al. (2004). Several categories of 147 potential environmental impacts were selected within the project framework as they were considered 148 to be relevant for aquaculture (Aubin 2013; Pelletier et al. 2007). They were the following: 1) 149 eutrophication ( $k g \mathrm{PO}_{4}$ eq.), which concerns the impacts on aquatic and terrestrial ecosystems 150 associated with nitrogen and phosphorus enrichment; 2) acidification ( $\mathrm{kg} \mathrm{SO}_{2}$ eq.), which assesses the 
151 potential acidification of ground and water due to the emission of acidifying molecules in the air, the 152 ground or in water; 3) climate change ( $\mathrm{kg} \mathrm{CO}$ eq.), which assesses the production of greenhouse 153 gases by the system; 4) the use of energy (MJ), which concerns all the energy resources used; 5) the use of net primary production $(\mathrm{kg} \mathrm{C})$, which represents the trophic level of products from the quantity of carbon used and derived from primary production. For some sites, the following were added: 6)

156 water dependence $\left(\mathrm{m}^{3}\right)$ defined as the amount of water flowing through the fish farm and required to

157 produce fish; 7) the utilization of the surface $\left(\mathrm{m}^{2}\right)$ which reflects the way the production system takes 158 over the land, including the production of inputs (in particular the crops necessary for the manufacture 159 of aquaculture feed). Work carried out on the LCA under the EVAD project was based on the experience of similar approaches already undertaken in aquaculture (Aubin and Van der Werf 2009; Aubin et al. 2009; Papatryphon et al. 2004).

162

\section{3. Results}

The approach was validated in the six aquaculture systems studied under the project. The diagnoses of the sustainability of aquaculture systems were first established for each area (territorial diagnoses, $\S$

166 3.1), then at global level by developing a synthesis of these diagnoses (into a meta-diagnosis, § 3.2). These diagnoses were undertaken at the criterion level, which is the most relevant analytical level to qualify the sustainability factors of these systems, and complemented by the LCA (§ 3.3).

31. Territorial diagnoses of aquaculture system sustainability

171 Typologies carried out by area (Lazard et al. 2009, 2010) revealed quite a large diversity in production

172 and regulatory systems. Leaving aside the Tangkit site (Indonesia) where aquaculture systems are

173 very homogeneous, three or four different farm types were identified in each area, regardless of 174 whether or not there was a large number of farms.

177 at the principle level in order to facilitate comparison. Working at this level made it possible to generate 178 general diagnoses by area which highlighted the strengths and the weaknesses of the relevant 179 aquaculture system. 
A database was built from the selections made by the actors from the different countries. It comprised

18313 principles (table 2), 64 criteria and 129 indicators (Rey-Valette et al. 2008). Despite system

184 diversity, 10 principles and 25 criteria were common to 4 of the 6 areas. The proportion of common

185 indicators was significantly lower with only 30 indicators common to three areas. Although the

186 technical systems studied in Indonesia were highly differentiated as regards both farming systems

187 (cages and ponds) and aquaculture operators (farmers and entrepreneurs), many criteria were

188 common to the two Indonesian areas of Tangkit and Cirata. This observation tended to show the

189 importance of cultural and institutional aspects for sustainability. Conversely, Cameroon, where

190 aquaculture is struggling to develop, was a particular case which stood out from other areas in terms

191 of principle selection and prioritization. This situation tended to indicate that the degree of maturity of

192 the sector was also a determining factor for sustainability.

193 Table 2 presents the number of criteria selected in at least three countries by principle, distinguishing

194 between those relating to farm sustainability, those relating to the evaluation of their contribution to

195 territorial sustainability and those concerning both levels. Furthermore, the analysis of the types of

196 criteria selected according to the area showed that actors tended to select criteria relating to aspects

197 which seemed to them to be problematic. This approach was therefore perceived by them as a

198 management and programming tool to facilitate progress in their aquaculture systems. This was a

199 different process to labelling approaches or certification schemes which are often linked to marketing

200 strategies and where the emphasis is on strengths in order to build the image of the sector.

201 Considering figure 2, Brittany proved to be relatively well placed in terms of sustainability with,

202 however, differentiated scores depending on the various principles. On the other hand, the

203 Mediterranean and the Philippines had more regular profiles which showed some homogeneity in the

204 results for all the principles, with no outstanding strengths/constraints. Lastly, Cameroon and

205 Indonesia had, like Brittany, uneven profiles based on the principles but at a lower level of

206 sustainability. This varying homogeneity in the scores is a fundamental result for defining sector-

207 specific accompanying policies.

208

209

210

211 33. Environmental diagnoses of aquaculture systems based on the LCA method 
Figure 3 reveals that there was no direct relationship between the level of intensification of the farming system and the level of impact. In particular, the Cirata fish farms in Indonesia (cages) and the bass

214 and bream production in the Mediterranean, also in cages, were both very intensive, but showed a very low level of impact for the former and a very high level for the latter. This might be explained by the species choice (predominantly planktivorous/omnivorous) and the goal of maximum productivity (by associating species: common carp and tilapia) in the first case and by the choice of carnivorous species (bass/bream) and a poor food conversion ratio in the second case, which was confirmed by Mungkung et al. (2013). The markedly lower impact of trout culture (Brittany) might be explained by its low FCR. In the case of polyculture in Cameroon, only two impact categories showed high levels: eutrophication and water dependency, due to the poor capacity of the system to make use of the nutrients provided by the inputs, combined with inadequate water management (Efole-Ewoukem et al. 2012).

224 Polyculture impacts were found to be relatively high in the Philippines. They showed the low productivity of the system and, as a result, the quantity of inputs did not produce sufficient output; and the same was true for land and water. In Pangasius fish farms in Tangkit, the predominant impact was the use of net primary production due to excess levels of fish meal (based on local species and trash fish) incorporated into the feed.

\section{Discussion} The ranking of areas with respect to sustainability obtained from the multicriteria evaluation corresponded, in terms of relative priority, to the classification obtained from the results of the life cycle assessment. In both cases, Brittany obtained the best scores whilst more extensive systems, which might have been thought to be closer to natural systems in their environmental dimension and therefore intuitively more "sustainable", scored much lower. In fact, at the studied sites, it appeared that intensive systems related to situations where farming regulatory and control systems were far more developed and effective.

238 At first sight, the environmental performance evaluated by LCAs was not consistent with the perception that emerged from the diagnoses established on the basis of criteria and principles selected by the actors in the various areas. In particular, the high level of environmental impact found in the Mediterranean cage farming system did not appear at all at farm level and only just at territorial 
level. This situation may be explained by two characteristics. LCA indicators (impact categories) relate 243 mainly to two levels: a local level (e.g. eutrophication or water use) and a global level (e.g. climate 244 change, acidification or the use of net primary production) or a mixture of the two levels (e.g. energy 245 use). For this reason, actors feel that cages placed in open surroundings where the water resource 246 seems to be endless, like the sea, have no impact on the environment. In contrast, trout fish farming in 247 Brittany is thought to have a higher impact as it uses fresh water, a natural resource considered to be 248 under threat. As a result, principles relating to territorial carrying capacity and ecological performance 249 at farm level were selected. However, when impacts were calculated in tonnes of fish, they were lower 250 than those found in Mediterranean marine cages.

251 The Filipino fish farms of Pampanga which are spread over significant areas and are therefore 252 assimilated to extensive practices, were not considered by actors to have worrying environmental 253 impacts despite high levels of impact on climate change and acidification per tonne of fish.

254 In the case of Cameroon, there was some consistency concerning the hot spot of the system, which 255 was the high release of nutrients into the environment (reflected by the eutrophication indicator).

256 The two Indonesian fish farming systems appeared particularly well optimized and their impact, 257 calculated in tonnes of product, was low. Nevertheless, worrying environmental impacts remained for 258 these two types of farming.

259 Generally speaking, these results showed no real concordance between local actors' preoccupations 260 as defined by the participatory approach and the information produced by LCAs, except indirectly 261 through production system efficiency. They were therefore clearly two complementary evaluation 262 approaches with different spatial levels of preoccupation as actors were not very sensitive to global 263 impacts. Perceptions of environmental issues depended greatly on resource availability and this was 264 not reflected by the LCA when it was calculated in units of product weight. These findings challenge 265 the use of LCAs in the context of certification or ecolabelling schemes (Mungkung et al. 2006; Pelletier 266 and Tyedmers 2008) as they could lead to standards or communication procedures that are 267 misunderstood or misinterpreted by local producers and decision-makers.

268

5. Conclusion 
Lessons learnt from work carried out in the various areas suggested a number of more general conclusions that demonstrated the value of the method.

1) Combining a participatory and procedural approach with the integration of international reference frameworks proved to be effective. A fair level of learning and appropriation was achieved during the evaluation exercise. Producers considered that the approach adopted (i.e. the co-construction of principles, criteria and indicators) was a management tool that could help in the development of their fish farms. The indicators were used because they were closely related to the farming characteristics in each of the countries. But comparisons were possible at criterion and principle levels. This approach is thus more appropriate than certain certification schemes which are generally viewed as external norms imposed on farming (Belton et al., 2012).

2) The lessons learnt from this project - one element of proof is the diversity in the choice of indicators - confirmed the idea that sustainable development cannot be fractal, i.e. have the same content regardless of scale. One dimension that appeared to be essential, although it is usually missing in the field of animal or vegetal productions, was that concerning the contribution of enterprises to the sustainable development of the territory in which they are located. This approach to sustainable development is close to the ecosystem approaches suggested by the Millennium Ecosystem Assessment (2005). Such an approach offers a positive vision of environmental protection and makes it more acceptable for actors.

3) Between coercion, mimicry and professionalization (Aggeri et al. 2005), which are different ways of adopting sustainable development; our approach clearly followed the third route. It emphasized the decisive importance of the choice of route for implementing sustainable development, for its adoption and the emergence of innovations within aquaculture systems.

4) Lastly, the use of the Life Cycle Assessment in this study showed that it is probably worthwhile involving stakeholders in weighting the impacts calculated by this standardized method, in order to adjust their relevance in contrasting territories. A complementary approach would consist in more effectively integrating into LCAs the sensitivity of territories to impacts, as was done by Pfister et al. (2009) for the use of water. Nonetheless, using the LCA made it possible to compare different situations with standardized indicators and to widen the field of evaluation to a global scale, where the political interest goes beyond that of the territory. 


\section{Acknowledgements}

The results reported in this article came from the "EVAD" Project ("Evaluation of aquaculture systems sustainability") carried out from 2005 to 2010 within the "Agriculture and Sustainable Development" Programme of the French National Research Agency (ANR, Agence Nationale de la Recherche).

The authors wish to thank all their partners for their active involvement in the "EVAD" Project: in Cameroun, AQUACAM fish farmers, Mr. S. Tangou, Dr V. Pouomogne, Dr Gabriel Toumba; in Cyprus, Mr. G. Georgiou, Mr. A. Petrou; in France, Mr. T. Gueneuc, Mr. A. Tocqueville, Mr. Philippe Riera, Mr. J.Y. Colleter, Ms E. Moraine; in Indonesia, Mr. D. Day, Ir Maskur, Mr. J. Haryadi, Dr. T.H. Prihadi, Prof K. Sugama, Mr. A.T. Shofawie; in the Philippines, Dr R.E. Ongtangco, Dr L. Bontoc, Dr R.D. Guerrero III, Ms M. Ocampo, Mr. R.N. Alberto. 


\section{References}

304

Aggeri, F., E. Pezet, C. Abrassart, and A. Acquier. 2005. Organiser le développement durable.

Expériences des entreprises pionnières et formation de règles d'action collective. Paris: VuibertAdeme [in French].

308

Argyris, C., and D. Schon.1996. Organizational Learning II. Theory, Method and Practice. Bruxelles: De Boeck Universite, Coll. Management.

Aubin, J. 2013. "Life Cycle Analysis as applied to environmental choices regarding farmed or wild caught fish." CAB Reviews 8: $n^{\circ} 011$.

314

Aubin, J., and H.M.G. Van der Werf. 2009. "Fish farming and the environment: A life cycle assessment approach." Cahiers Agricultures 18(2-3): 220-226 [in French, English summary].

Aubin, J., E. Papatryphon, H.M.G. Van der Werf, and S. Chatzifotis. 2009. "Assessment of the environmental impact of carnivorous finfish production systems using life cycle assessment". Journal of Cleaner Production 17 (3): 354-361.

Belton, B., F. Murray, J. Young, T. Telfer, and D.C. Little. 2010. "Passing the Panda Standard: A TAD Off the Mark?" Ambio 39: 2-13. DOI 10.1007/s13280-009-0009-4

326 Boulanger, P.-M. 2007. "Political uses of social indicators: Overview and application to sustainable development indicators." International Journal of Sustainable Development 10(1-2): 14-32.

Boyd, C.E., A.A. McNevin, J. Clay, and H.M. Johnson. 2005. "Certification issues for some common aquaculture species". Review of Fisheries Sciences 13: 231-279. 
CML. 2001. http://cml.leiden.edu/software/data-cmlia.html

338 Consensus. 2005. Defining Indicators for Sustainable Aquaculture Development in Europe. A multi339 stakeholder workshop held in Ostende, Belgium, 21-23 November 2005. Oostende: EAS (European 340 Aquaculture Society).

342 Edwards, P. 1999. Aquaculture and Poverty: Past, Present and Future Prospects of Impact. A

343 Discussion Paper prepared for the Fifth Fisheries Development Donor Consultation, Rome, Italy (2234424 February 1999).

346 Efole Ewoukem, T., J. Aubin, O. Mikolasek, M.S. Corson, M. Tomedi Eyango, J. Tchoumboue, H.M.G.

347 van der Werf, D. Ombredane. 2012. Environmental impacts of farms integrating aquaculture and 348 agriculture in Cameroon. Journal of Cleaner Production 28: 208-214.

FAO. 1995. Code of Conduct for Responsible Fisheries. Rome: FAO.

FAO. 2008. Building an ecosystem approach to aquaculture. FAO Fisheries and Aquaculture 353 Proceedings 14. Rome: FAO

FAO. 2010. The State of World Fisheries and Aquaculture. Rome: FAO.

Fraser, E.D., A.J. Dougill, W.E. Mabee, M. Reed, and P. McAlpine. 2006. "Bottom up and top down: 358 Analysis of participatory processes for sustainability indicator identification as a pathway to community

359 empowerment and sustainable environmental management". Journal of Environmental Management 360 78: $114-127$. 
GFCM (General Fisheries Commission for the Mediterranean). 2010. Indicators for sustainable

363

365

Jahn, T., M. Bergmann and F. Keil. 2012. "Transdisciplinarity: Between Mainstreaming and Marginalization." Ecological Economics 79: 1-10.

Jolliet, O., M. Saadé, and P. Crettaz. 2005. Life Cycle Assessment. How to understand and carry out a LCA. Lausanne, Switzerland: Presses polytechniques et universitaires romandes/Collection gérer l'environnement [in French].

development of aquaculture. Third coordinating meeting of the working groups, 24-26 February, 2010, 62-73. Rome: FAO.

Henriksson, P.J.G., J.B. Guinee, R. Kleijn, and G.R. de Snoo. 2012. "Life cycle assessment of aquaculture systems-a review of methodologies". International Journal of Life Cycle Assessment 17: 304-313.

Hilden, M., and U. Rosenström. 2008. "The Use of Indicators for Sustainable Development." Sustainable Development 16: 237-240.

Irz, X., and R.J. Stevenson. 2005. Aquaculture and poverty. A case study of five coastal communities in the Philippines. In Aquaculture Compendium. Wallingford, UK: CAB International.

ISO (International Organization for Standardization). 2006a. Principles and Framework, in Life Cycle Assessment, E. management, Editor. European Commitee for Standardization: Brussels.

ISO (International Organization for Standardization). 2006b. Requirements and guidelines in Life Cycle Assessment, E. Management, Editor. European Commitee for Standardization: Brussels.

\section{lenvironnement [in French].}

Lazard, J., A. Baruthio, S. Mathé, H. Rey-Valette, E. Chia, O. Clément, P. Morissens, et al. 2009.

"Adaptation of aquaculture system typologies to the requirements of sustainable development." Cahiers Agricultures 18 (2-3): 199-210 [in French, English summary]. 
Lazard, J., A. Baruthio, S. Mathé, H. Rey-Valette, E. Chia, O. Clément, P. Morissens, et al. 2010.

394

395

396

397

398

399

400

401

402

403

404

405

406

407

408

409

410

411

412

413

414

415

416

417

418

419

420

421

"Aquaculture system diversity and sustainable development: fish farms and their representation." Aquatic Living Resources 23: 187-198.

Mathé, S., O. Brunel, H. Rey-Valette, and O. Clément. 2006. Recensement des initiatives en faveur de la durabilité de l'aquaculture. Montpellier, France: CEP/UICN-Université de Montpellier 1 [in French].

Merino, G., M. Barange, J.L. Blanchard, J. Harle, R. Holmes, I. Allen, E.H. Allison, et al.2012. "Can marine fisheries and aquaculture meet fish demand from a growing human population in a changing climate? Global Environmental Change 22 (4): 795-806. doi:10.1016/j.gloenvcha.2012.03.003

Millennium Ecosystem Assessment (MEA). 2005. Ecosystems and Human Well-being: Synthesis. Washington, DC: Island Press.

Mungkung, R.T., H.A.U. de Haes, R. Clift. 2006. "Potentials and limitations of life cycle assessment in setting ecolabelling criteria: A case study of Thai shrimp aquaculture product." International Journal of Life Cycle Assessment 11: 55-59.

Mungkung, R., J. Aubin, T.H. Prihadi, J. Slembrouck, H.M.G. van der Werf, M. Legendre. 2013. Life Cycle Assessment for environmentally sustainable aquaculture management: a case study of combined aquaculture systems for carp and tilapia. Journal of Cleaner Production 57: 249-256.

Naylor, R.L., R.J. Goldberg, J.H. Primavera, N. Kautsky, M.C.M. Beveridge, J. Clay, C. Folke, et al. 2000. "Effects of aquaculture on world fish supplies." Nature 405: 1017-1024.

Papatryphon, E., J. Petit, S.J. Kaushik, H.M.G. Van der Werf. 2004. "Environmental impact assessment of salmonid feeds using Life Cycle Assessment." Ambio 33(6): 316-323. 
Pelletier, N.L., N.W. Ayer, P.H. Tyedmers, S.A. Kruse, A. Flysjo, G. Robillard, F. Ziegler et al. 2007. "Impact categories for life cycle assessment research of seafood production systems: Review and prospects." International Journal of Life Cycle Assessment 12: 414-421.

Pelletier, N. and, P. Tyedmers. 2008. Life Cycle Considerations for Improving Sustainability Assessments in Seafood Awareness Campaigns. Environmental Management 42 : 918-931.

Pfister, S., A. Koehler, S. Hellweg. 2009. "Assessing the Environmental Impacts of Freshwater Consumption in LCA." Environmental Science \& Technology 43: 4098-4104.

Prabhu, R., Colfer, C., Dudley, R. 2000. Guidelines for developing, testing and selecting criteria and indicators for a sustainable management of forests. Montpellier, France: Cirad (ed.) [in French, English summary].

Rey-Valette, H., F. Laloë, and J. Le Fur. 2007a. "Introduction to the key issue concerning the use of sustainable development indicators." International Journal of Sustainable Development 10(1-2): 4-13.

Rey-Valette, H., J.P. Blancheton, F. René, J. Lazard, S. Mathé, and E. Chia. 2007b. "The sustainable development: A challenge for Mediterranean marine aquaculture." Cahiers Agricultures 16 (4): 1-10 [in French, English summary].

Rey-Valette H., O. Clement, J. Aubin, S. Mathe, E. Chia, M. Legendre, D. Caruso et al. 2008. Guide to the co-construction of sustainable indicators in aquaculture. Montpellier, France: Cirad (ed.) [In French and English].

Schaltegger S., M. Beckmann and E. G. Hansen. 2013. "Transdisciplinarity in Corporate Sustainability: Mapping the Field." Business Strategy and the Environment 22(4): 219-29.

Tacon, A.G.J., and M. Metian. 2008. "Global overview on the use of fish meal and fish oil in industrially compounded aquafeeds: Trends and future prospects." Aquaculture 285: 146-158.

Tlusty, M., H. Tausig, T. Taranovski, M. Jeans, M. Thompson, M. Cho, M. Eppling, et al. 2012. "Refocusing Seafood Sustainability as a Journey Using the Law of the Minimum". Sustainability 4: 
449

450

451

452 Wijkström, U. 2003. Short and long-term prospects for consumption of fish. Veterinary Research 453 Communication 27(suppl. 1): 461-468.

454

455 WWF. 2008a. Tilapia Aquaculture Dialogue Draft Standards Version1.0.

456 (http://www.worldwildlife.org/what/globalmarkets/aquaculture/WWFBinaryitem10225.pdf).

457

458 WWF. 2008b. Pangasius aquaculture dialogue. Meeting Summary.

459 (http://www.worldwildlife.org/what/globalmarkets/aquaculture/WWFBinaryitem11128.pdf) 


\section{List of tables and figures}

Table 1. Location of the aquaculture systems studied according to three criteria: environment, regulation and intensification (stocking density)

460

461 Table 2. Number of criteria proposed by the guide and selected for each principle according to the 462 dimension of sustainable development

463

464

465

466

467 Figure 1. The 8 stages of the EVAD project methodology

468 Figure 2. Evaluation at principle level (Pn) of: A) the sustainability of aquaculture enterprises by 469 country; and B) the contribution of aquaculture enterprises to territorial sustainability by country.

470 The larger the area of the kite, the more sustainable the aquaculture system

471

472 Figure 3. Life-Cycle-Assessment (LCA)-based environmental profile of the 6 aquaculture systems

473 studied under the EVAD project

474 Kites compare the relative environmental impact for seven impact categories, for the 6 fish production 475 systems. Points closer to the centre of the graph display the lowest environmental impact.

476 Values for Water Dependence have been log10-transformed

477

478 
Table 1. Location of the aquaculture systems studied according to three criteria: environment, regulation and intensification (stocking density)

\begin{tabular}{|c|c|c|c|c|}
\hline \multirow[t]{2}{*}{ Environment } & \multicolumn{2}{|c|}{ Rural area } & \multicolumn{2}{|c|}{ Coastal area } \\
\hline & Low density & High density & Low density & High density \\
\hline Weak regulation & $\begin{array}{c}\text { Monoculture of } \\
\text { Pangasius in fresh } \\
\text { water ponds } \\
\text { Indonesia } \\
\text { (Tangkit, Sumatra, } \\
\text { Indonesia) } \\
\\
\text { Family-scale } \\
\text { commercial } \\
\text { polyculture } \\
\text { (tilapia-catfish) } \\
\text { in fresh water ponds } \\
\text { (Western Cameroon) }\end{array}$ & & $\begin{array}{c}\text { Extensive } \\
\text { shrimp-fish } \\
\text { polyculture in } \\
\text { brackish water } \\
\text { coastal } \\
\text { ponds } \\
\text { (Pampanga, } \\
\text { Philippines) }\end{array}$ & \\
\hline & & $\begin{array}{c}\text { Carp + tilapia } \\
\text { farming in } \\
\text { floating cages in } \\
\text { the Cirata } \\
\text { reservoir } \\
\text { (West Java, } \\
\text { Indonesia) }\end{array}$ & & $\begin{array}{l}\text { Sea bream and bass } \\
\text { culture in floating } \\
\text { cages in the } \\
\text { Mediterranean Sea } \\
\text { (France and Cyprus) }\end{array}$ \\
\hline $\begin{array}{l}\text { Strong } \\
\text { regulation }\end{array}$ & & $\begin{array}{l}\text { Intensive farming } \\
\text { of rainbow trout } \\
\text { in fresh water } \\
\text { flow-through } \\
\text { raceways } \\
\text { (Brittany, France) }\end{array}$ & & \\
\hline
\end{tabular}


Table 2. Number of criteria selected by at least three countries for each principle according to the dimension of sustainable development

481

$482 \mathrm{~S}=$ Sector $\mathrm{T}=$ Territorial $\mathrm{C}=$ Common (Several indicators were common to the sector and territory 483 dimension). $\left(^{*}\right)$ They relate to the number of criteria selected by several sites, other site-specific 484 criteria may have been jointly picked.

485

486

487

488

489

490

491

492

493

494

495

496

497

498

499

500

501

502

503

504

505

\begin{tabular}{|c|c|c|c|}
\hline & $\mathrm{S}$ & $\mathrm{T}$ & $C\left({ }^{*}\right)$ \\
\hline \multicolumn{4}{|l|}{ Environmental } \\
\hline $\begin{array}{l}\text { P3. Ensure that natural resources and the environmental carrying } \\
\text { capacity are respected }\end{array}$ & 1 & 2 & 1 \\
\hline P4. Improve the ecological yield of the activity & 2 & & \\
\hline P5. Protect biodiversity and respect animal well-being & 1 & & \\
\hline \multicolumn{4}{|l|}{ Social } \\
\hline P1. Contribute to meeting nutritional needs & 1 & & 3 \\
\hline P8. Strengthen sectoral organization and identity & 1 & & \\
\hline \multicolumn{4}{|l|}{ P9. Strengthen companies' social investment } \\
\hline \multicolumn{4}{|l|}{ Economic } \\
\hline P6. Increase the capacity to cope with uncertainties and crises & 3 & 1 & \\
\hline P7. Strengthen the long-term future of farms & 3 & & \\
\hline P2. Develop approaches that promote quality & & & 1 \\
\hline \multicolumn{4}{|l|}{ Institutional } \\
\hline P10. Strengthen the role of aquaculture in local development & 1 & 1 & \\
\hline P11. Promote participation and governance & & 1 & \\
\hline P12. Strengthen research and sector-related information & 3 & & \\
\hline $\begin{array}{l}\text { P13. Strengthen the role of the State and of public actors in } \\
\text { establishing sustainable development }\end{array}$ & 2 & & 1 \\
\hline
\end{tabular}


510

511

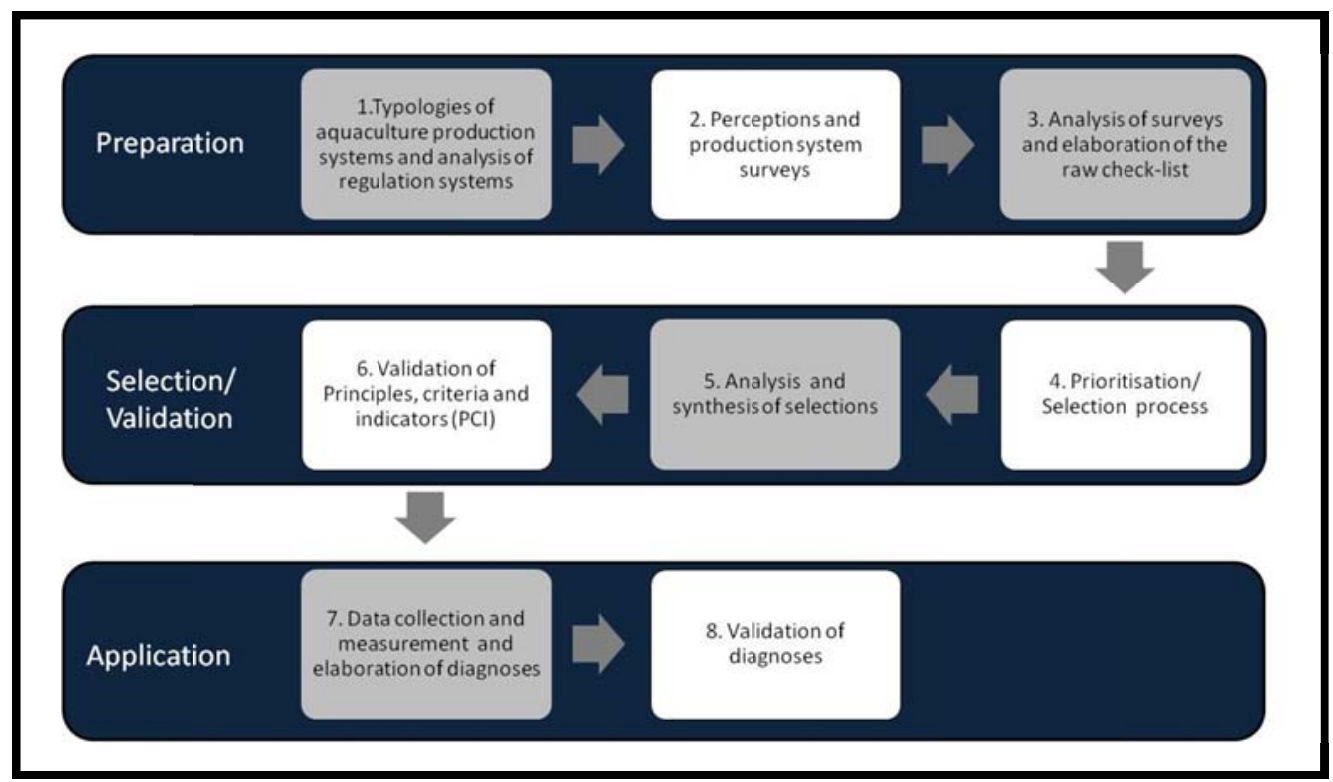

514

515

516

517

518

519

520

521

522

523

524

525

526

527

528

529

530

531

532

533

534

535

536

537

538

539

540

541

542

543

544

545

546 
548 Figure 2. Evaluation at principle level (Pn) of: A) the sustainability of aquaculture enterprises by

549 country; and B) the contribution of aquaculture enterprises to territorial sustainability by country.

550 The larger the area of the kite, the more sustainable the aquaculture system

\section{1}

552

\section{A}

554

555

556

557

558

559

560

561

562

563

564

565

566

567

568

569

570

571

572

573

574

575

576

577

578

579

580

581

582

583

584

585

586

587

588

589

590

591

592

593

594

595

596

597

598

599

600

601

602

603

604
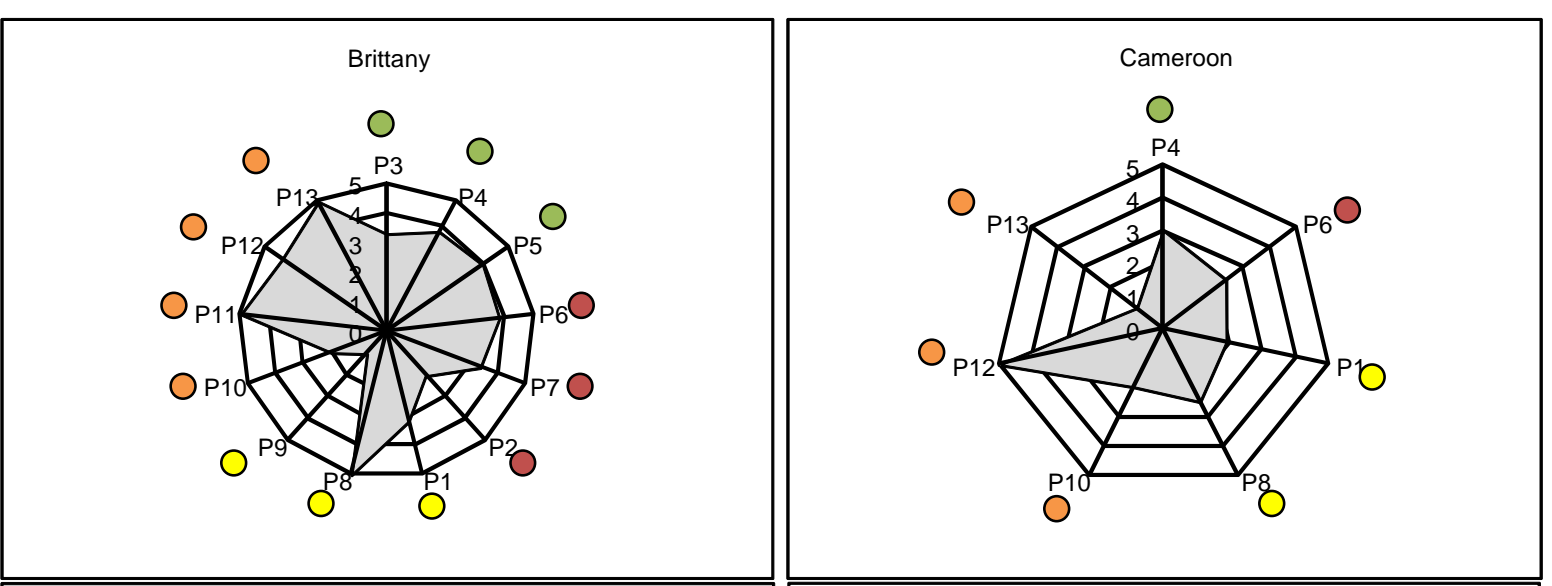

Mediterranean
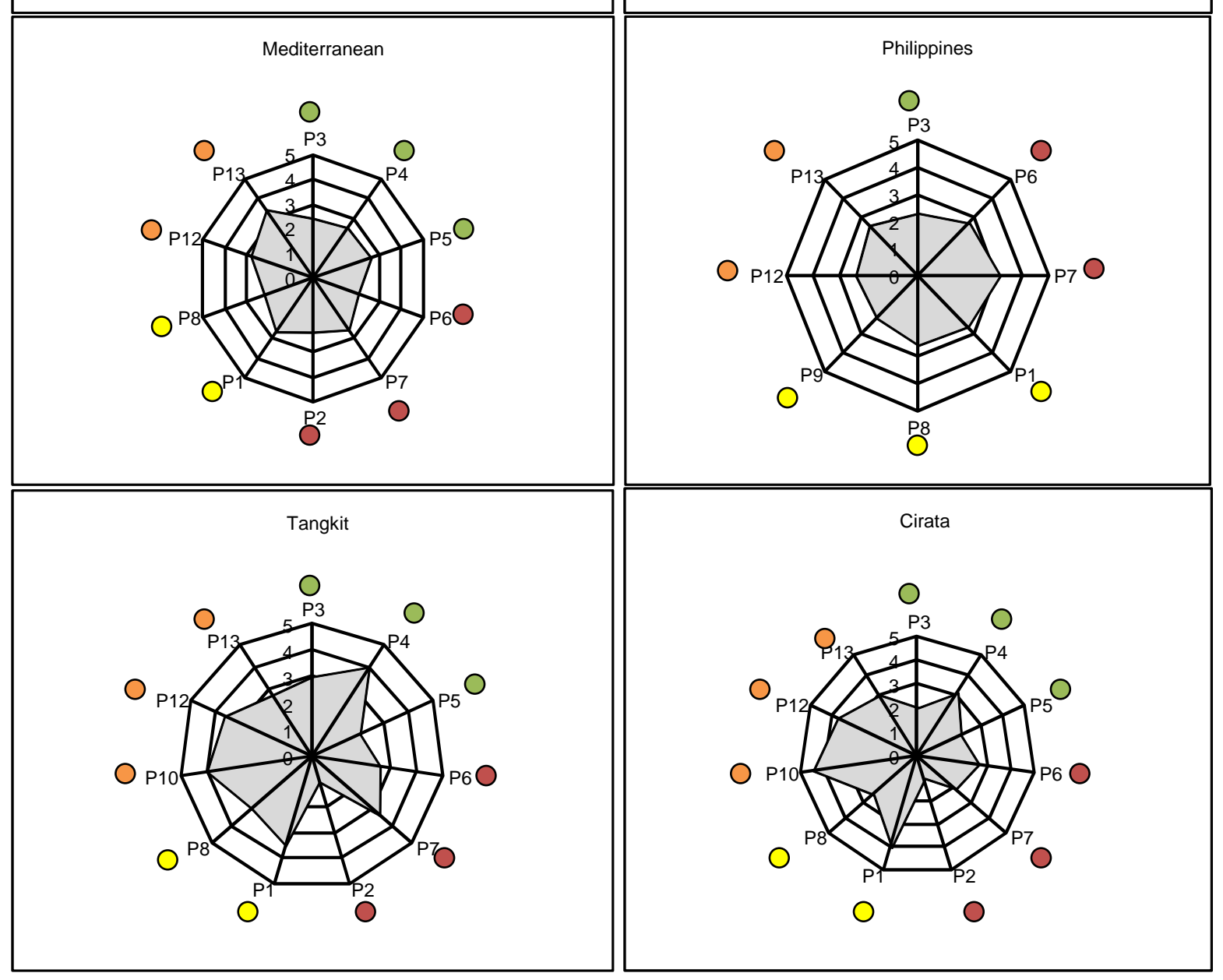
605

606

607

608 B

609

610

611
612

613

614

615

616

617

618

619

620

621

622

623
624

625

626

627

628

629

630

631

632

633

634

635

636

637

638

639

640

641

642

643

644

645

646

647
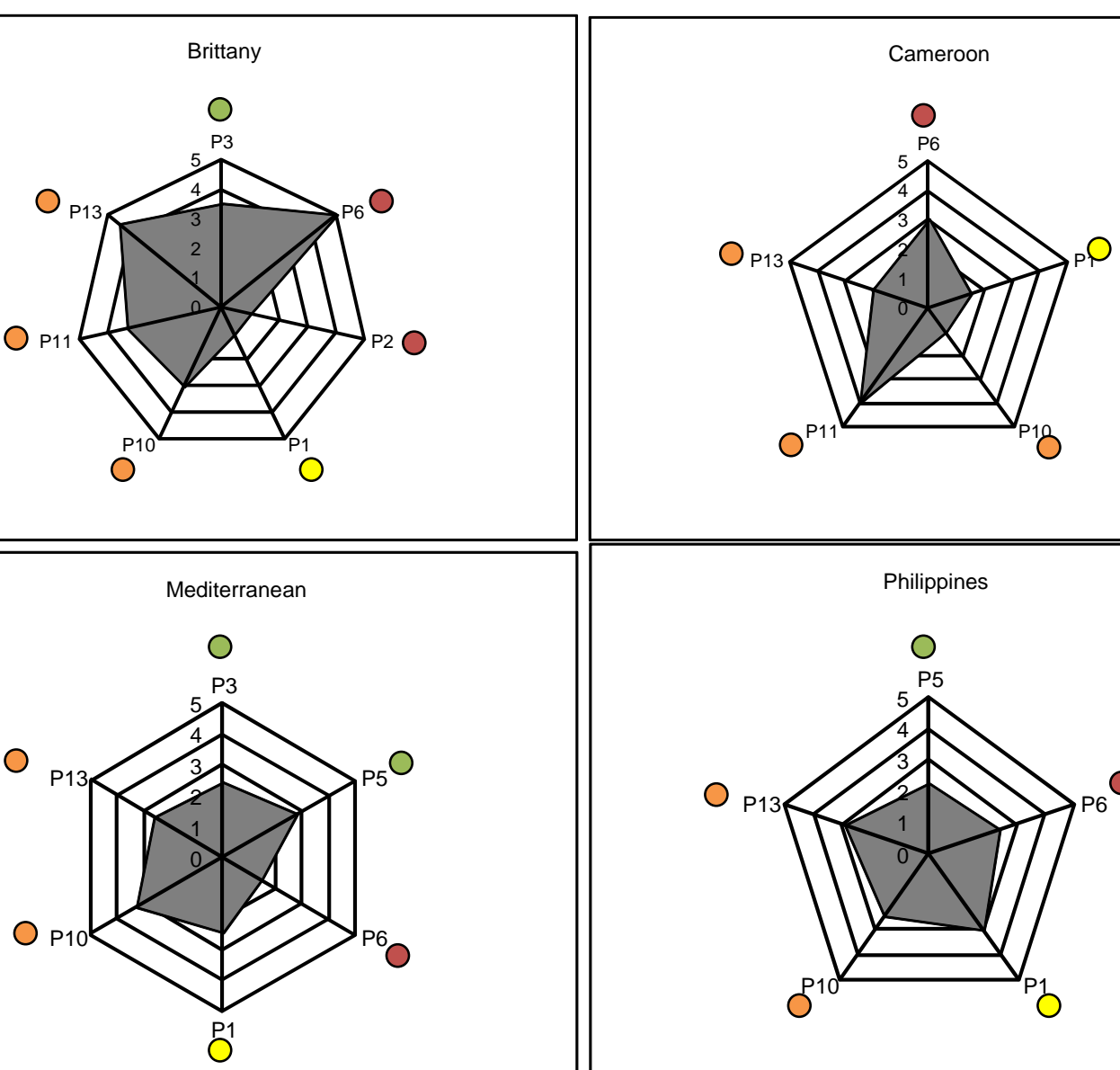

648

649 Legend

650

651

652
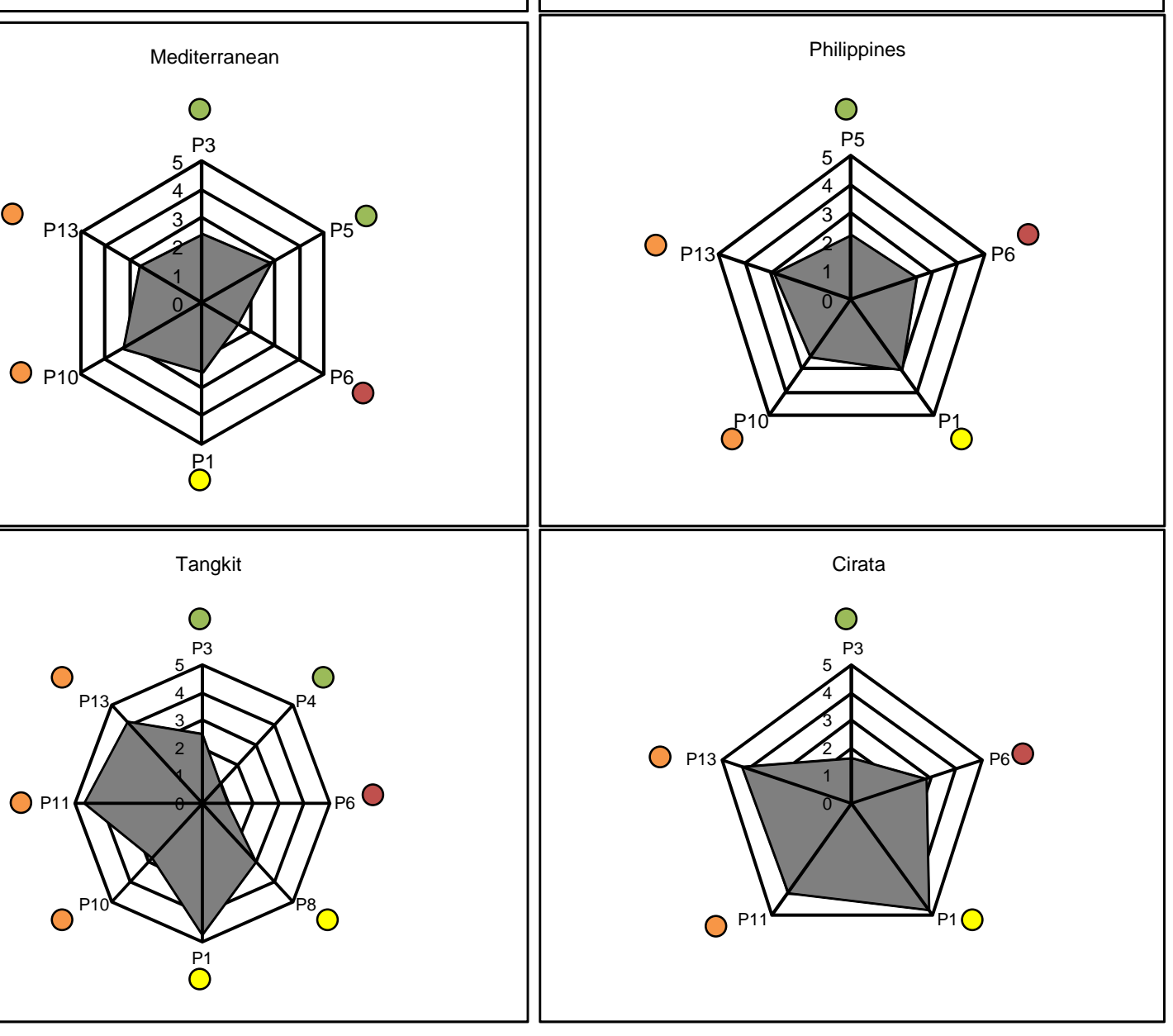
653

654 
655 Figure 3. Life-Cycle-Assessment (LCA)-based environmental profile of the 6 aquaculture

656 systems studied under the EVAD project

657 Kites compare the relative environmental impact, for seven impact categories, for the 6 fish production

658 systems. Points closer to the centre of the graph display the lowest environmental impact.

659 Values for Water Dependence have been log10-transformed.

660

661

662

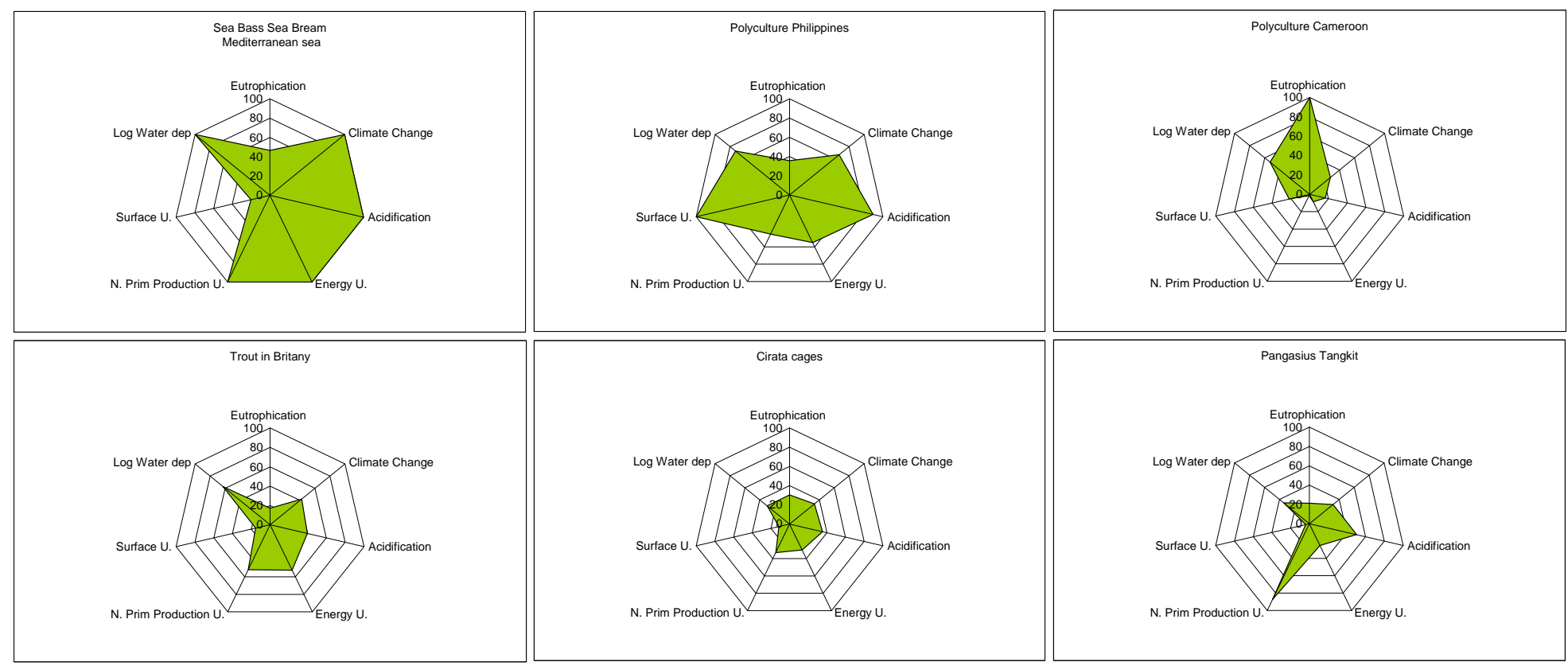

663

664

665

666

667

668

669 